\title{
THE TENDENCIES OF THE DYNAMICS OF PREMATURE MORTALITY RATE IN EUROPE
}

DOI: https://doi.org/10.18509/AGB.2021.08

UDC: $314.14(4)$

\section{Simona-Andreea Ursache (m. Dumitriu) ${ }^{1}$, Ionel Muntele ${ }^{1,2}$, Marinela Istrate ${ }^{1}$}

\author{
${ }^{I}$ „Alexandru Ioan Cuza” University of Iasi, Faculty of \\ Geography and Geology,Department of Geography, Iasi, Romania. \\ ${ }^{2}$ Romanian Academia, Iasi, Romania.
}

corresponding author: simona_93u@yahoo.com

submitted: 22.04 .2020

accepted: 10.07 .2020

published: 10.10 .2020

\begin{abstract}
The contemporary society is privileged today, more than at any other time in history, because access to health services, education, mobility of the population, increased life expectancy and the eradication of deadly diseases have led society to a better world. However, billions of people still have a low standard of life, living at the limit of poverty, illness, social exclusion and premature death.

In this study we intend to carry out a analysis of the dynamics of age-standardized overall premature mortality rate (from 30 to under 70 years) for four major non-communicable diseases: cardiovascular diseases, cancer, diabetes mellitus and chronic respiratory diseases (1990-2015), some of the most expressive demographic indicators of the vulnerability of human communities. We will try to overcome a possible correlation between this indicator and other socio-demographic indicators considered by the World Health Organization to be important: the unemployment rate, total expenditure on health as a proportion of gross domestic product (GDP) (WHO estimates) (\%), consumption of alcohol, percentage of children vaccinated against measles etc.

From a methodological point of view, both the general trends analyzed at the level of the European countries and the specific trends observed at the national level are concerned. The data used are part of the database of the World Health Organization, EUROSTAT, www.indexmundi.com». The territorial analysis mediated by the GIS will permanently accompany the statistical methods, constituting the specific geographical contribution essential to the whole approach. Following the documentation from the specialized literature, the consultation of the statistical data and the realization of the graphic and catalog materials, we would like to carry out a qualitative analysis, confirming the initial hypotheses.
\end{abstract}

Keywords: premature mortality, health, Europe, medical services, standard of living.

\section{INTRODUCTION}

Mortality is a demographic indicator with profound economic, social, psychological and cultural implications. In the past, infant mortality was very high and babies were considered the most vulnerable component of a society. Mortality in general has experienced oscillations during wars, outbreaks, pandemics or infectious diseases, but the emergence of microbial theory and epidemiological transition have consistently contributed to its decline in developed countries. The death rate indicates the incidence of deaths at 1000 persons in the case of a given population[1-2].

Premature mortality ,refers to people who die of a health condition earlier than expected"(measured in years of life lost) [3]. In most countries, it is generally considered premature death before 70 years (75 years in the USA). The worldwide reduction of premature deaths is a priority in the area of health policies; the United Nations aims to reduce premature deaths due to incommunicable diseases by $1 / 3$ by $2030[4-5]$. This indicator also captures the quality of life in a country, the life expectancy and the health status of the population. Health, well-being or the economic progress are just some of the concepts most used and studied today, and they are intended to express those aspects which contribute to a better quality of life. Depending on the context, they can mean a certain social position or material prosperity, a certain physical or mental state of well-being, safety, accessibility to medical services, quality education or even the lack of disease. The present globalization, as well as the previous one, besides the economic progress has deepened the inequalities existing worldwide and has transformed the health into an extremely important 
vector, able to make the difference between life and death. Angus Deaton was of the opinion that in general, respiratory diseases, tuberculosis or malnutrition are usually seen as "diseases of poverty" and cancer, heart disease or stroke as

\section{METHODOLOGY}

From a methodological point of view, this study analyzes the dynamics of premature mortality in Europe, between 1990 and 2015. The main indicator analyzed is the age-standardized overall premature mortality rate (from 30 to under 70 years) for four major non-communicable diseases: cardiovascular diseases, cancer, diabetes mellitus and chronic respiratory diseases (1990-2015). To have a more complex analysis we correlated this indicator with other socioeconomic indicators relevant to our study: per capita alcohol consumption among people aged 15+ within a calendar year (liters of pure alcohol, total expenditure on health as a proportion of gross domestic product (GDP) (WHO estimates) (\%), Percentage of children vaccinated against measles (\%), unemployment rate (\%), Gross domestic product (GDP), US\$ per capita, Malignant neoplasms, all ages, per 100 000, by sex (agestandardized death rate), Life expectancy at birth (years). The European continent is the area of study of our scientific approach. The final result of the analysis is the achievement Hierarchical Cluster Analysis (exploratory methods, typically applied with an eye to determining how $n$ entities -

\section{RESULTS AND CONCLUSIONS}

After The Second World War, the East-West disparities have deepened even further in Europe, with people from less developed or war-affected countries knowing rather late the health benefits compared to more developed countries. Even though trends in mortality have been decreasing (for both categories of countries), health is not the only way to improve the demographic structure of a society. In the contemporary society, WHO and other major organizations (EU, NATO;) have drawn attention to the importance of reducing premature mortality by discussing factors that could directly influence premature mortality: childhood obesity, tobacco and tobacco marketing legislation (exemplified by Finland or Turkey that have succeeded through tougher taxation policies to reduce alcohol consumption), creating urban spaces conducive to physical activity, regular blood pressure measurement, new tobacco taxation measures, use of electronic medical records, access to previous medical information facilitating personalized care and treatment (we mention the case of the State of Israel which has succeeded by "diseases of abundance"[6]. Even though post-1980 progress in the field of public health, rising life expectancy and a steady drop in mortality have led to higher quality of life, premature mortality in some European countries still remains high.

sentences, NPs, words, subjects, etc. - can be grouped into $\mathrm{m}<\mathrm{n}$ groups/clusters that exhibit high within-group similarity and low similarity to other groups) [7] and the realization of a Principalcomponent analysis proposed by Hotelling (1933), one of the most familiar methods of multivariate analysis (which uses the spectral decomposition of a correlation coefficient or covariance matrix [8]. In order to deepen the analysis, two ACP have been carried out for two distinct periods: 1990-2000 and 2000-2015. The data used was collected using the World Health Organization database; in some cases the missing data were filled in using the database www.indexmundi.com. The territorial analysis mediated by the GIS has always accompanied the statistical methods, constituting the specific geographical contribution essential to the entire scientific endeavor.

Hypothesis presentation

H1: Premature mortality is directly influenced by the standard of living (expressed by GDP) and the way of life.

H2: Despite the public health policies promoted, in Europe there are still countries with a high primary mortality rate.

electronic registries to increase the efficiency of the medical system), the rapid access to information leading to an increase in the effectiveness, or very important, the promotion of cardiovascular health color through public health policies that emphasize the importance of nutrition, reducing salt consumption, proper treatment in high blood pressure, educating the population through first aid measures in the case of vascular accidents and access to medication and modern medical infrastructure [9].

The study area, the European continent, was chosen because it represents a standard of civilization and modernity, and the social, demographic and economic policies it promotes directly influence the Romanian society. As mentioned above, in order to overcome the trends of the dynamics of premature mortality in Europe, we chose as reference period (1990-2015), analyzed with the help of the AHC and the ACP. In the case of Cluster Hierarchical Analysis, as we can see in figure 1, there is a correlation between premature mortality and the analyzed factors, the intraclass variance being 
lower than that between the classes, the east-west and north-south contrasting trends being visible. Eight classes are distinguished, each with welldefined demographic profiles. Classes 5 and 4, mainly comprise former communist countries (Hungary, Poland, Belarus, Estonia, Latvia, Lithuania, Romania, Republic of Moldova), countries which are mostly in the last places (Republic of Moldova, Ukraine, Belarus) and in the graph life expectancy at birth. With a demographic and socioeconomic track marked by political influences, both premature mortality (maximum: Romania, Belarus, Portugal) and other indicators analyzed are very high compared to the countries in the north or west of the continent. They are distinguished from the other classes by: High values of alcohol consumption per capita (maximum value in Estonia, Lithuania, Belarus, Czech Republic), low levels of unemployment (Serbia, Croatia, Slovakia) in the proportion of GDP health expenditure (Romania, Belarus, Estonia, below $6,5 \%)$.

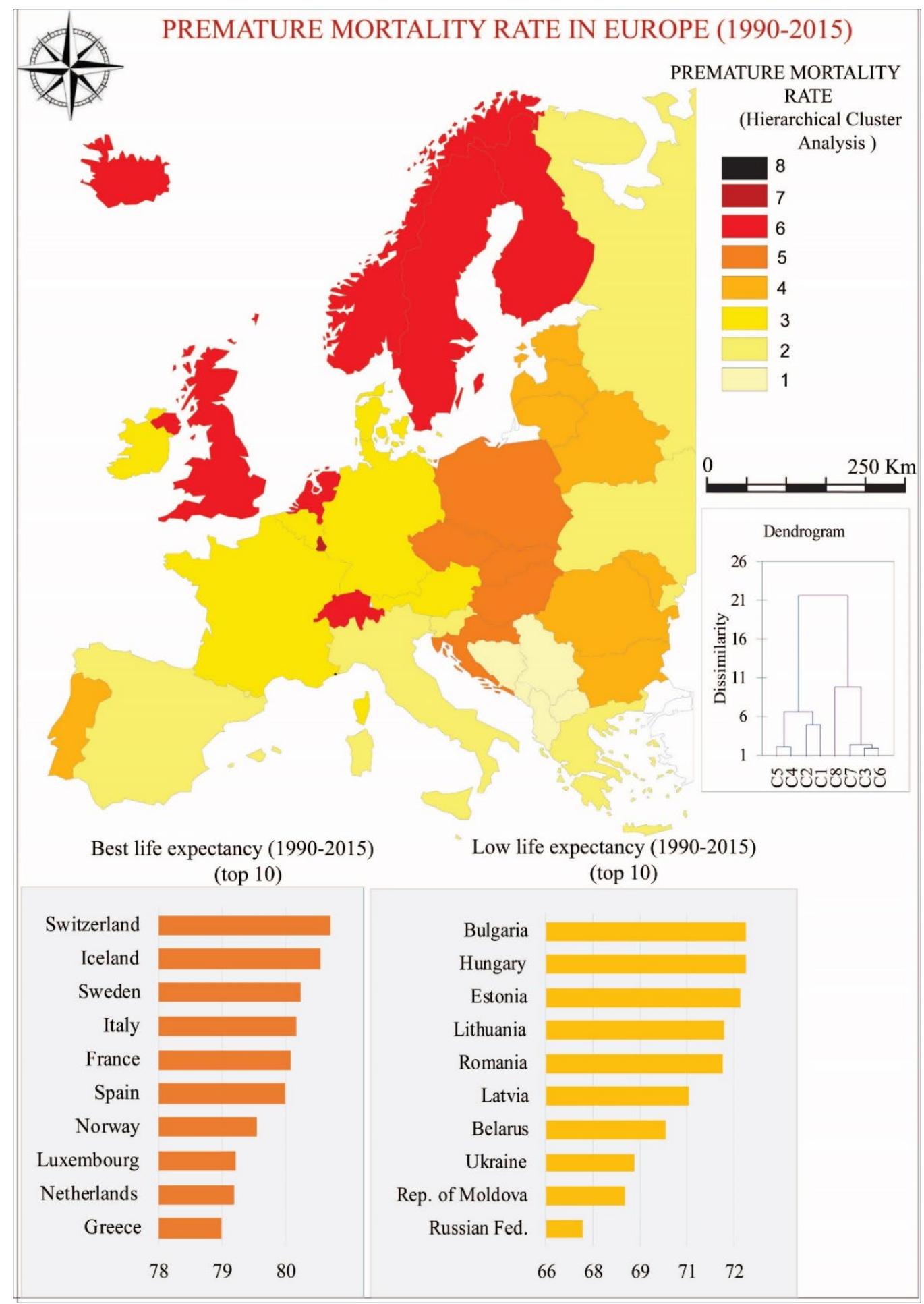

Figure 1. Premature mortality rate in Europe. Source: OMS, 1990-2015. 
In Portugal, premature mortality was directly influenced by the high rate of infant and adolescent mortality, as well as cardiovascular mortality, infectious diseases (HIV) or mortality from external causes (among men) [10-11].

During the period studied, we can observe a positive evolution of the analyzed indicator, specific to the countries in the period of demographic transition. The incidence of malignant neoplasms is high in Croatia, Slovakia, Poland, Latvia, Lithuania, Romania, Estonia, Czech Republic (over 180 deaths per 100,000 inhabitants) and low life expectancy (below 70 years Russia, Ukraine). After the 1990s numerous studies have tried to explain the causes of the deterioration of the health status and the increasing trends of mortality in the former Soviet countries, reaching the conclusion that there is talk of a health crisis based on political and socioeconomic uncertainty [12].

In classes 1 and 2, countries are represented in the Mediterranean area (Italy, Spain, Greece, Malta) and countries located in the Balkan peninsula (Albania, Bosnia and Herzegovina, Macedonia, Montenegro, Serbia) or in the eastern of the continent (Russia, Ukraine). They appear on the cartogram with very open color ranges showing in the form of well delimited areas with high premature mortality rates. In the case of the Balkan States of Albania, Macedonia, Bosnia and Herzegovina, Montenegro or even Serbia, the situation of premature mortality and the factors analyzed was directly influenced by the military conflicts between the ethnic groups in the years ' 90 . In some of these countries alcohol consumption is low (Islam is the dominant religion in Albania or Kosovo, being widely present in the other states), and the unemployment rate is very high compared to the countries of classes 4 and 5 (Albania 16\%, Montenegro 19\%, Macedonia 29\% - for the period 2010-2015, in previous periods being even higher in some cases).

In the case of Serbia, the main causes of premature mortality are cardiovascular diseases, cancer and diabetes, closely linked to the diet rich in animal fats and carbohydrates [13]. In the Mediterranean countries, the classification in this class is also determined by the migratory component (after 1990 Spain and Italy received important migratory flows from other continents or from the east of Europe: Romania, Republic of Moldova, Ukraine and so on, looking for places of work and a better standard of living). Alcohol consumption is average (7.81), the share of expenses in the field of health quite significant (around 9\%), the unemployment rate is very high (Greece $22 \%$, Spain $23 \%$, for the period 2010-2015), incidence of cancer around 150 deaths/ 100,000 place (average values against the maximum value of 234 deaths Hungary and the minimum of 118 deaths in Cyprus) and the life expectancy quite high (around 80-81 years) [1416]. As we can see, in the composition of the same classes there are groups of countries with distinct particularities, which justify the relevance of choosing complementary factors that overestimate the dynamics of premature mortality and causal relationships.

Class 8 also integrates class 7 and class 3-6. Only Monaco is part of Class 8 (best known as a State with a quality of life, the GDP and a high life expectancy at birth). Investments in health in GDP are below $5 \%$, because life expectancy is very high, mortality is low and the health system is one of the most modern in Europe. In relation to the number of inhabitants, we consider that the proportion invested in health is relevant.

Class 7 includes two other small States Luxembourg and San Marino, where the economic factors considered may have a significant role (GDP), along with high life expectancy, low unemployment. We can see that cancer incidence is directly influenced by living standards (financial resources are vital for cancer because medicine, surgical interventions and recovery as well as the result of healthy living are quite expensive; We no longer consider hospitalization or special analyzes in specialized hospitals in America or Turkey, Japan, which are generally not settled by national health systems).

Class 3 includes: Austria, Belgium, Germany, Denmark, France and Ireland, countries with an average premature death rate, life expectancy at birth over 80 years, high GDP, share of health expenditure from GDP 10-11\% (double against Romania, Albania, Belarus, Latvia). Class 6 are mainly Nordic countries: Finland, Norway, Sweden, Iceland along with the UK, Switzerland and the Netherlands, countries known for their remarkable progress in health and standard of living, average alcohol consumption, GDP spending on health in around $8-10 \%$, very high life expectancy at birth (maximum value in Switzerland, followed by Iceland, Sweden), lower migratory flows compared to Germany, France and Mediterranean countries (except UK), low unemployment rate (Iceland - under 6\%, Norway, Switzerland - under 4\%). 


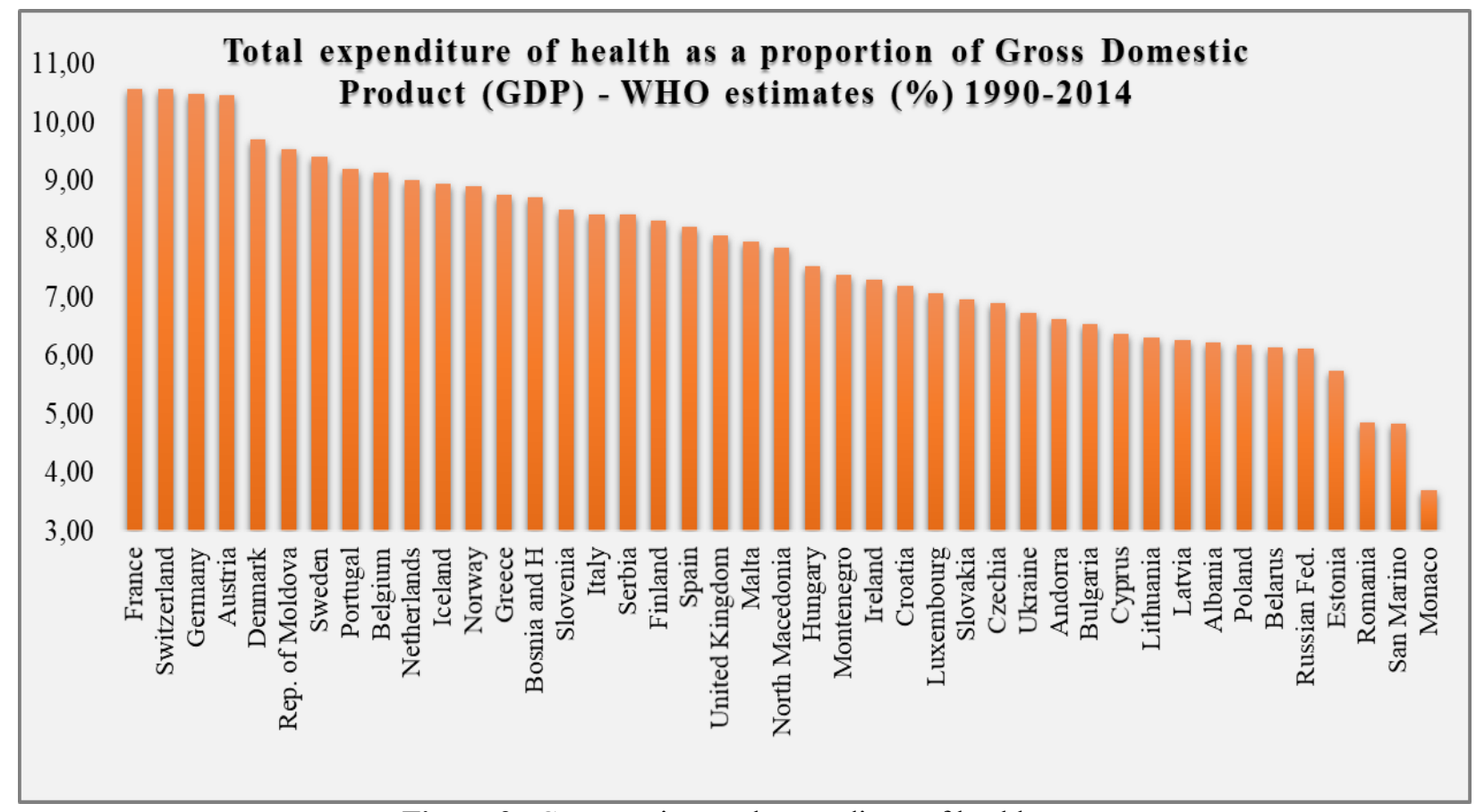

Figure 2. Comparative total expenditure of health as a proportion of GDP (1990-2014).Data source: OMS

As we can see in the graph of Figure 2, we cannot say that the proportion of GDP spending on health directly influences premature mortality rate as there are countries with low and medium-sized analyzed indicator rates and investments of more than $10 \%$ of GDP (France, Switzerland, Germany, Austria). Countries with high premature mortality rates in relation to the share of invested expenditure (Republic of Moldova, Bosnia and Herzegovina, Portugal, Greece), countries with high premature mortality rates and low investment shares (Romania, Russia, Estonia, Belarus) and very low premature mortality and small investments (San Marino, Monaco), with a high standard of living. In the case of Analysis in the main components, in order to have relevant results, we have analyzed the proposed indicator over two periods: 1990-2000 and 2000-2015.

Using the Varimax rotation we have tried to highlight the arrangement on the factorial axes and the grouping of countries according to the specific factor(s). In the period 1990-2000 (See fig. 3), premature mortality correlates positively to alcohol consumption, the share of the population vaccinated against rubella (contagious disease with potential severe complications, fatal especially for children), and cancer deaths and correlates negatively to the share of GDP expenditure in health, unemployment, the GDP and most with life expectancy at birth. The strong correlation between alcohol consumption and cancer-related deaths shows that these factors are a favorable context for reducing premature mortality [17]. „Alcohol is nutritionally unnecessary, a toxin, and addictive; and heavy episodic and chronic heavy use are associated with increased risks of fatal injury, cancer, hypertension, and stroke" [18]. Another interesting correlation is the GDP's correlation with life expectancy at birth. Cancer deaths link positively to premature mortality, alcohol consumption and the share of the vaccinated population.

On the two distinct axes that form, the extremes are the Monaco and Macedonia countries.On the left, with positive values, countries are emerging where premature mortality is directly influenced by the increased incidence of cancer-related deaths, the lower share of the population vaccinated against measles (generally former socialist countries but also Portugal, the United Kingdom) and at the bottom with negative values, Countries where the unemployment rate is higher (Poland, Ukraine, Serbia, Macedonia). On the right side, with positive values, are high-income countries where alcohol appears as a determining factor (Luxembourg, Ireland, Austria, Monaco) and health expenditure appears in the lower key part (France, Spain, Greece, Italy). 


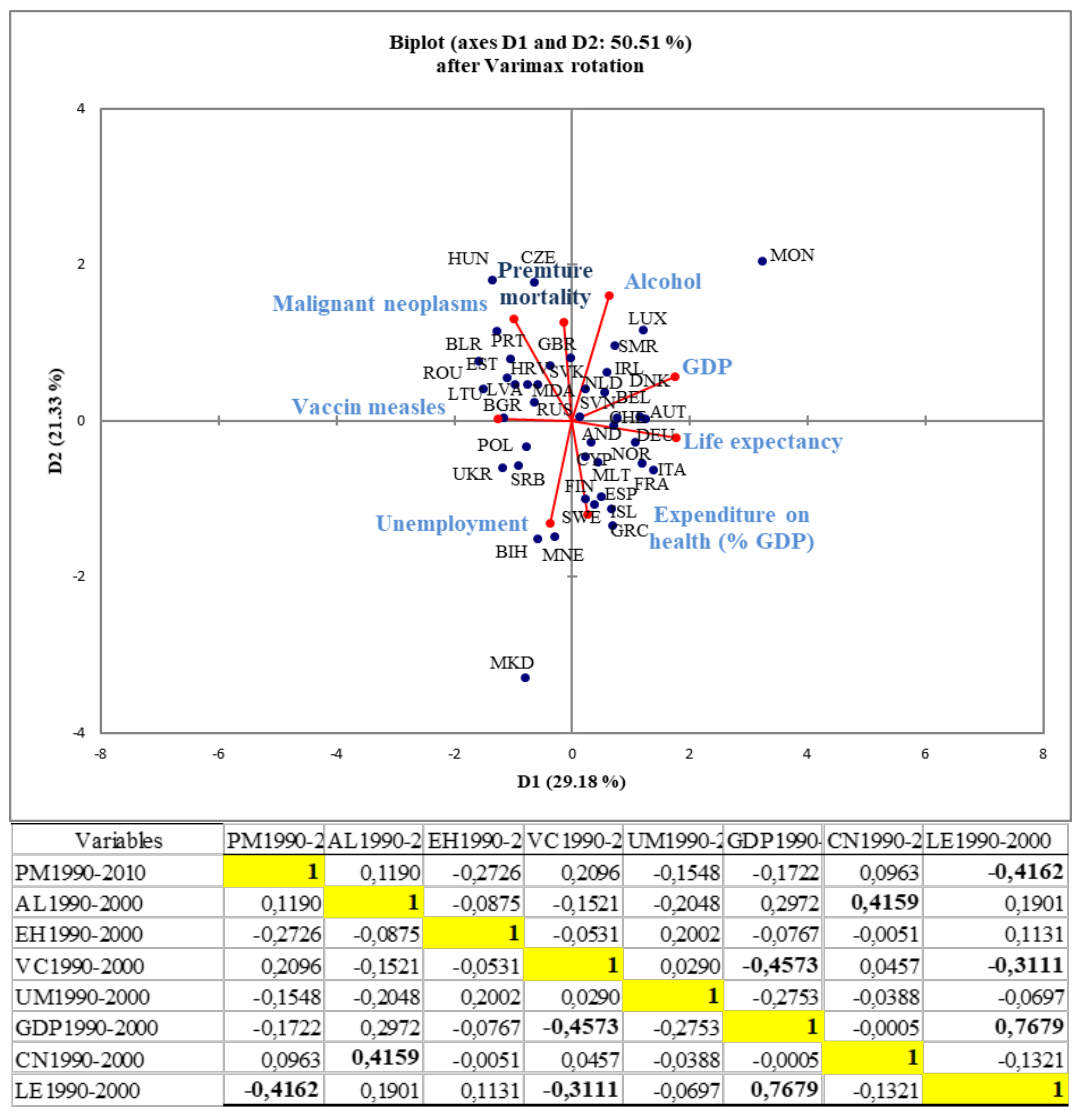

Figure 3. Principal-component analysis and Pearson Correlation Matrix (1990-2000).

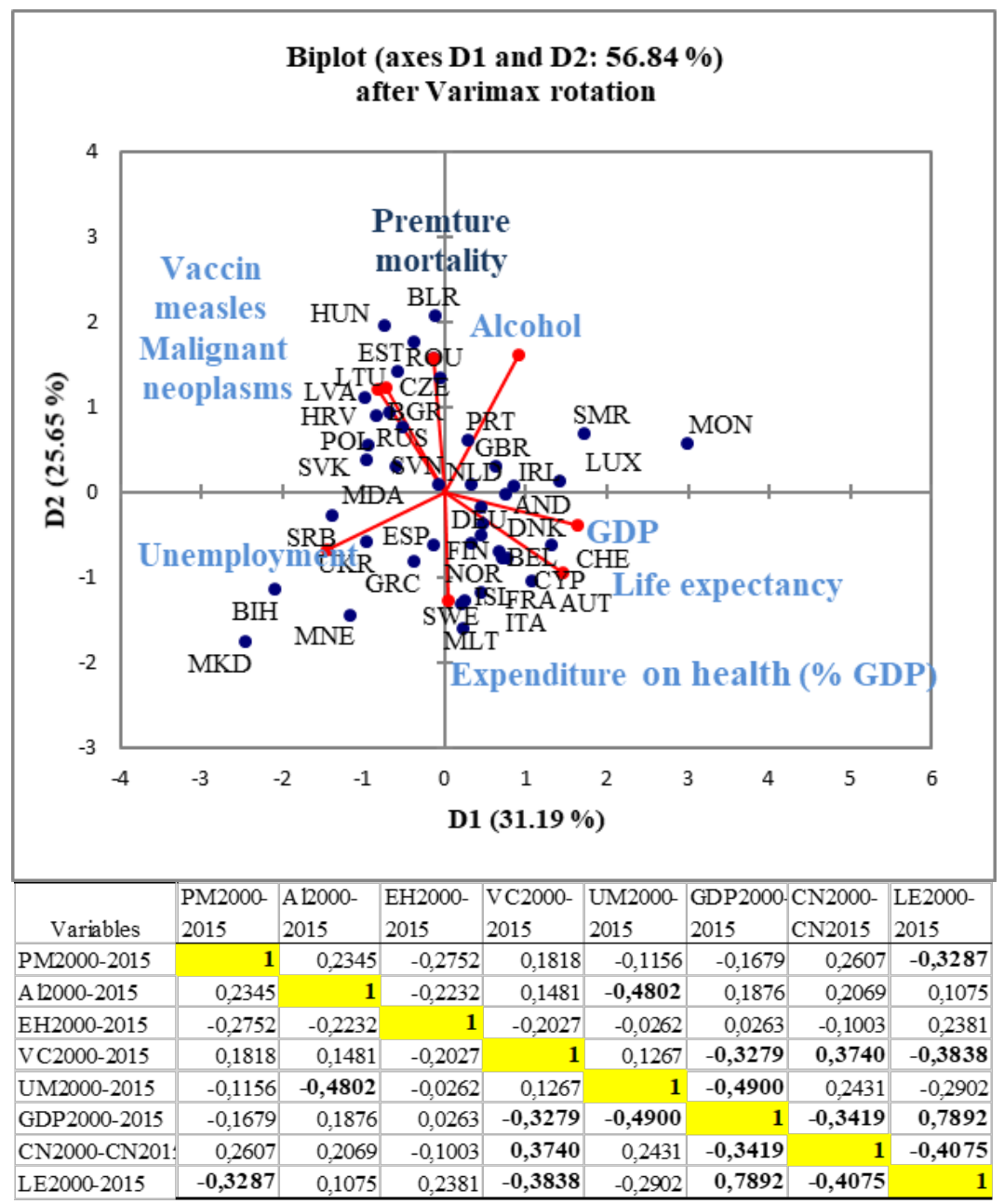

Figure 4. Principal-component analysis and Pearson Correlation Matrix (2000-2015). 
For the period 2000-2015, premature mortality correlates positive and negative to the same factors. For this period, alcohol consumption and unemployment rates are key drivers in reducing premature mortality, with a strong negative correlation. The positive correlation between the GDP and life expectancy remains evident. Cancerrelated deaths link positively during this period with the share of the vaccinated population against measles, and negatively to the GDP and life expectancy. Cancer deaths correlate positively for this period with the proportion of the population vaccinated against measles, and negatively with GDP and life expectancy. The extreme limits of the graph remain all the countries of Monaco and Macedonia, and of the noticeable differences we mention: the situation of the former communist countries also remains in this worrying period, the unemployment rate increases in several states, the consumption of alcohol decreases and as a result most likely to implement the policies of taxation applied by some countries, and life expectancy, GDP and spending on health remain the determining factors for developed countries. [1921]. In 2003 the World Health Organization ranks by age groups in mortality in the 192 Member States according to child mortality ( $0-5$ years) and adult mortality (15-59 years), using 1999 data. The countries of Europe fall within the first 3 of the 5 straits proposed by the who. As we can see the trends shown in the table below are largely those we have achieved through the two statistical methods presented. (See Tab.1).

Table 1. Mortality stratum in Europe. Data source: OMS [22]

\begin{tabular}{|c|c|c|c|}
\hline $\begin{array}{c}\text { Europe } \\
\text { mortality } \\
\text { stratum }\end{array}$ & Description & $\begin{array}{l}\text { Broad } \\
\text { grouping }\end{array}$ & Member states \\
\hline Eur-A & $\begin{array}{l}\text { Europe with very low } \\
\text { child andvery low adult } \\
\text { mortality }\end{array}$ & Developed & $\begin{array}{l}\text { Andorra, Austria, Belgium, Croatia, } \\
\text { Cyprus, Czech Republic, } \\
\text { Denmark,Finland, France, Germany, } \\
\text { Greece, Iceland, Ireland, } \\
\text { Italy,Luxembourg, Malta, Monaco, } \\
\text { Netherlands, Norway, Portugal, San } \\
\text { Marino, Slovenia, Spain, Sweden, } \\
\text { Switzerland, United Kingdom. }\end{array}$ \\
\hline Eur-B & $\begin{array}{l}\text { Europe with low child } \\
\text { and low adult mortality }\end{array}$ & Developed & $\begin{array}{l}\text { Albania, Bosnia and Herzegovina, } \\
\text { Bulgaria, Poland, Romania, Slovakia, } \\
\text { Republic of Macedonia, Serbia, } \\
\text { Montenegro. }\end{array}$ \\
\hline Eur-C & $\begin{array}{l}\text { Europe with low child } \\
\text { and high adult } \\
\text { mortality }\end{array}$ & Developed & $\begin{array}{l}\text { Belarus, Estonia, Hungary, Latvia, } \\
\text { Lithuania, Republic of Moldova, Russian } \\
\text { Federation, Ukraine. }\end{array}$ \\
\hline
\end{tabular}

\section{CONCLUSION}

Reducing premature mortality is one of the most important challenges of contemporary society and the World Health Organization. As we have seen the trends of the dynamics of the analyzed indicator cannot be exposed in the general sense for the continent of Europe as there are well-delimited areas that have distinct particularities and are directly influenced by certain factors. In this sense, quite high values of premature mortality in the former communist countries (Russia, Ukraine, Romania, Estonia, Latvia, Lithuania, Bulgaria) but also in southern Europe (Portugal, Spain, Italy) or the Balkan Peninsula (Macedonia, Albania) are evident. Bosnia and Herzegovina, Montenegro, Greece). The Nordic countries and Switzerland, Monaco, Luxembourg or the Netherlands are true role models in the field of public health and quality of life policies by increasing public health spending, promoting a healthy diet, outdoor movement, etc. We can state the fact that statistical analyzes have largely confirmed the proposed hypotheses. The main contribution of the article is to highlight some positive or negative tendencies in decreasing the rate of the analyzed indicator. The results of the study also present a series of limitations and constraints, generated by the sometimesincomplete information or the contradictory nature of the analyzed parameters. The concrete mode of manifestation and their causality can only be surprised by case studies at national level, taking into account the economic, social and political manifestations of the time. A more complete view of the trends observed also implies the correlation of the indicator analyzed with other elements of demographic analysis, such as the incidence of premature births, the policies promoted by the countries regarding the healthy lifestyle, the specialized medical infrastructure in the treatment of cancer, cardiovascular diseases, respiratory diseases and diabetes, nationally and 
health insurance policies and so on. As Romania occupies the first places in Europe both in the case of infant mortality and in the case of premature mortality, it is necessary at national level to study the analyzed indicator and to apply a long-term strategy to improve the quality of life.

\section{ACKNOWLEDGEMENT}

This work was co-funded by the European Social Fund, through Operational Programme Human Capital 2014-2020, project number POCU/380/6/13/123623, project title $<<\mathrm{PhD}$ Students and Postdoctoral Researchers Prepared for the Labour Market!>>

\section{REFERENCES}

[1] Warf Barney. Encyclopedia of Human Geography, SAGE Publication, United States of America, 2006.

[2] Trebici Vladimir. Mică enciclopedie de demografie, Editura Științifică și Enciclopedică, București, 1975.

[3] Truong-Minh Pham, Lorraine Shack, Winson Y. Cheung. Introduction of a novel measure of premature mortality caused by chronic conditions: real-world examples from prostate and testis cancers in Canada, 1980e2015, Annals of Epidemiology 37, pp. 81-83, 2019.

[4] https://www.un.org/sustainabledevelopment/health/

[5] Avdeev Alexandre. Populations et tendances démographiques des pays européens (1980-2010), Population (Vol. 66), pp. 9-133, 2011.

[6] Deaton Angus. MAREA EVADARE sănătatea, bogăția și originile inegalității, Editura Litera, 2017.

[7] https://www.sciencedirect.com/topics/computer-science/hierarchical-cluster-analysis

[8] https://www.sciencedirect.com/topics/medicine-and-dentistry/principal-component-analysis

[9]http://www.euro.who.int/en/health-topics/Health-systems/pages/news/news/2017/07/reducing-premature-deathsfrom-ncds-by-45-a-bold-vision-discussed-by-ncd-programme-directors-in-moscow

[10] Canudas-Romo, V., Glei, D., Gómez-Redondo, R., Coelho, E. \& Boe, C. Évolution de la mortalité dans la péninsule Ibérique au cours de la seconde moitié du XXe siècle. Population, vol. 63,(2), pp.319-343, 2008.

[11] Meslé, F. \& Vallin, J. Mortalité en Europe : la divergence Est-Ouest. Population, vol. 57,(1), pp. 157-197, 2002.

[12] Grigoriev, P. Crise sanitaire et tendances de la mortalité par cause en Biélorussie (1965-2008). Population, vol. 67,(1), pp. 7-38, 2012.

[13] Santric Milicevic, M., Bjegovic, V., Terzic, Z., Vukovic, D., Kocev, N., Marinkovic, J., \& Vasic, V. Serbia within the European context: An analysis of premature mortality. Population health metrics, pp. 7-12, 2009.

[14] J.Ferlaya, D.M.Parkinb, E.Steliarova-Fouchera. Estimates of cancer incidence and mortality in Europe in 2008. European Journal of Cancer,Volume 46, Issue 4, pp.765-781, 2010.

[15] Blum A., Monnier A.. „Recent mortality trends in the USSR: New evidence”, Population Studies, 43(2), pp. 211-241, 1989.

[16] Cornia G. A., Paniccià R. „The transition mortality crisis: Evidence, interpretation, and policy responses”, in Cornia G. A., Paniccià R. (eds.), The Mortality Crisis in Transitional Economies, Oxford, Oxford University Press, pp. 3-37, 2000.

[17] Macya T. Jonathan, O'Rourkeb P. Holly, Seoa Dong-Chul, Pressonc C. Clark, Chassinc Laurie. Adolescent tolerance for deviance, cigarette smoking trajectories, and premature mortality: A longitudinal study, Preventive Medicine 119, pp. 118-123, 2019.

[18] Evans-Polce J. Rebecca J , Staff Jeremy, Maggs L. Jennifer. Alcohol abstention in early adulthood and premature mortality: Do early life factors, social support, and health explain this association?, Social Science \& Medicine 163, pp. 71-79, 2016.

[19] Pearce Alison \& all. Productivity losses due to premature mortality from cancer in Brazil, Russia, India, China, and South Africa (BRICS): A population-based comparison, Cancer Epidemiology 53, pp. 27-34, 2018.

[20] Awuor Luckrezia, Melles Stephanie. The influence of environmental and health indicators on premature mortality: An empirical analysis of the City of Toronto's 140 neighborhoods, Health and Place 58, 2019.

[21] Cao Bochen, Bray Freddie, Ilbawi André, Soerjomataram Isabelle. Effect on longevity of one-third reduction in premature mortality from non-communicable diseases by 2030: a global analysis of the Sustainable Development Goal health target, Lancet Global Health 6, e1288-1296, 2018.

[22] WHO List of Member States by WHO region and mortality stratum http://www.who.int/whr/2003/en/member_states_182-184_en.pdf 